\title{
Does lumbar surgery for chronic low-back pain make a difference?
}

Fairbank J, Frost H, Wilson-MacDonald J, Ly-Mee Y, Barker K, Collins R; for the Spine Stabilisation Trial Group. Randomised controlled trial to compare surgical stabilisation of the lumbar spine with an intensive rehabilitation programme for patients with chronic low back pain: the MRC spine stabilisation trial [published erratum appears in BMJ 2005;330(7506):1485]. BMJ 2005:330 (7502):1233. Epub 2005 May 23.

Background: The commonplace problem of chronic low-back pain often results in disability severe enough to cause longterm absences from work and inability to carry out the normal activities of daily living. Individuals with chronic low-back pain often show evidence of disc narrowing and osteoarthritis of the lumbar spine. Spinal fusion, a surgical operation that may involve the use of interbody cages, bone grafts or posterior spinal instrumentation, is used to relieve the pain and increase mobility and function. In the United States, the frequency of spinal operations has risen from 11000 procedures in 1996 to 37000 in 2001. Complications risked in surgery include dural tears, bleeding, neurologic deficits and infection. Although the rate of spinal fusion procedures to address low-back pain have increased dramatically in North America, the evidence supporting the use of this procedure is weak; its superiority over conservative approaches has not been established.

Question: For patients who have had chronic low-back pain for at least 12 months and who are considered candidates for surgical stabilization of the lumbar spine, does surgery lead to better patient outcomes (as measured by the Oswestry disability index) than intensive rehabilitation?

要

Methods: The authors conducted a randomized controlled trial set in 15 centres across the United Kingdom. Only surgeons with expertise in spinal fusions participated.
Patients 18-55 years of age with at least 12 months of chronic low-back pain (with or without referred pain) were eligible, irrespective of previous discectomy or nerve-root decompression. They were included in the study if both patient and clinician were uncertain which treatment was preferable.

Blinding in the study was impossible. Those allocated to rehabilitation underwent a 3-week $(5 \mathrm{~d} / \mathrm{wk})$ outpatient program led by physiotherapists and usually including a clinical psychologist; these group received education, cognitive-behavioural therapy and individually tailored training for strength, flexibility, spine stabilization and cardiovascular fitness. In the surgical intervention group, the specific spinalfusion technique to be used was left to the operating surgeon.

At 6,12 and 24 months after treatment, the outcomes of primary interest were measured with a standardized shuttle walking test and the Oswestry disability index, which is scored from 0 (no disability) to 100 (total disability or bedridden). Secondary outcomes were measured with the 36-question shortform general questionnaire (SF36) for quality of life, the modified Zung depression index and the somatic perception questionnaire for patient anxiety. Any complications that occurred were noted. Findings were analyzed on the principle of intention to treat.

Results: The investigators recruited 349 patients and randomized 176 to surgery and 173 to conservative rehabilitation.
Losses to follow-up at 24 months after treatment were high: when Oswestry score was considered as the main primary outcome measure, the loss was $16 \%$ for the rehabilitation and $32 \%$ for the surgical group. Crossovers from the rehabilitation group to the surgical fusion group were frequent (28\%). $\mathrm{Pa}$ tients improved in both treatment arms, with a fall in mean Oswestry scores of $27 \%$ (from 47 to 34 ) in the surgery group and $20 \%$ (from 45 to 36 ) in the intensive rehabilitation group. Patients who had surgery experienced the greater reduction (mean imputed difference 4.5, $95 \%$ confidence interval $[\mathrm{CI}]$ 0.8-8.2). Walking-test and secondary outcome measures did not differ significantly between the groups. Nineteen patients (11\%) had intraoperative complications, of whom 11 required further surgery for dural tears, excessive bleeding or loss of fixation. There were no complications in the rehabilitation group.

Commentary: This study shows that relief of disability caused by low-back pain was significantly greater, statistically, in patients treated surgically with spinal fusion. The authors powered their study to identify a 4-point difference in Oswestry scores between groups. Whether 4 points out of 100 represents a difference that is clinically detecable and important to patients remains unclear. The confidence intervals cannot exclude a benefit from surgery of as high as $8 \%$ or as little as $1 \%$.

This trial is strengthened by its use of randomization, a sufficiently large sample of patients, a pragmatic trial design, an outcome analysis based on intention to treat, and validated outcome measures. The loss to follow-up, crossovers and inability to blind at least the outcome assessors were major limitations. The fact 


\section{Practice}

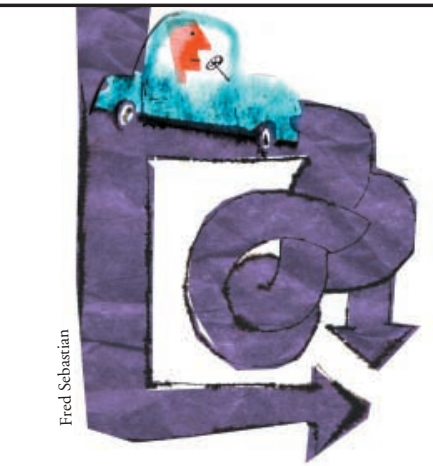

nonoperative approaches such as watchful waiting or treatment with placebo. ${ }^{2}$

Evidence is moderate to strong that physical conditioning programs that include a cognitive-behavioural approach reduce the number of sick days taken by workers with chronic low-back pain compared with usual care. ${ }^{3}$

Practice implications: Lumbar fusion surgery in patients with chronic low-back pain does not appear to offer any major benefit in outcomes over conservative rehabilitation programs incorporating physical activity and cognitive-behavioural therapy. Patients undergoing lumbar fusion may have a slightly lower but clinically unimportant decrease in disability scores in exchange for an increased risk of complications, higher medical costs and no difference in quality of life at 2 years after surgery.

\section{Mohit Bhandari}

Brad Petrisor

Division of Orthopaedic Surgery

Department of Surgery

Jason W. Busse

McMaster University

Brian Drew

Spine Unit

Hamilton Health Sciences-General

Hospital

Hamilton, Ont.

\section{References}

1. Ivar Brox J, Sorensen R, Friis A, $\mathrm{Ny}_{-}$ gaard $\mathrm{O}$, Indahl A, Keller A, et al. Randomized clinical trial of lumbar instrumented fusion and cognitive intervention and exercises in patients with chronic low back pain and disc degeneration. Spine 2003;28:1913-21.

2. Gibson JN, Waddell G. Surgery for degenerative lumbar spondylosis [Cochrane review]. Cochrane Database Syst Rev 2005;(2):CD001352

3. Schonstein E, Kenny D, Keating J, Koes B, Herbert R. Physical conditioning programs for workers with back and neck pain: a Cochrane systematic review. Spine 2003;28:E391-5.

\section{Chers lecteurs et lectrices, pourriez-vous nous accorder un moment?}

Le sondage annuel auprès des lecteurs du JAMC débute le 7 septembre. En nous parlant un peu de vous et de ce que vous pensez du JAMC, vous nous aiderez à améliorer encore le journal. Pendant deux semaines, lorsque vous rendrez visite au journal électronique, nous vous demanderons de passer une fois par la page du sondage. Nous espérons que vous accepterez de faire ce détour qui contribuera à nous garder sur la bonne voie. 